\title{
LA TRANSPARENCIA Y EL DERECHO DE ACCESO A LA INFORMACIÓN PÚBLICA EN ARGENTINA
}

\author{
Tesista \\ Mariel Inés Farioli \\ Director de tesis \\ Horacio A. Capanegra \\ Codirector de tesis \\ Oscar A. Costa
}

En el marco del proceso de reformas gubernamentales que se está llevando a cabo en numerosos países ( $y$ en diferentes niveles de gobierno) desde finales del siglo XX, tendientes a rediseñar el funcionamiento del Estado, fortalecer las instituciones y generar un aparato estatal más eficiente y transparente (Banco Mundial, 1997), el derecho de acceso a la información pública y la transparencia surgen como temas de agenda en los estados, como elementos coadyuvantes de consolidación democrática, básicamente para aumentar la participación ciudadana, promover la rendición de cuentas sobre las acciones de gobierno y combatir la corrupción. Estas iniciativas encontraron correspondencia en las reformas conocidas como New Public Management (NPM) que estaban siendo aplicadas por los países de la (OCDE) desde fines de los '70 (Ramírez, 2009). Por su parte, Estados Unidos fue uno de los países promotores de este nuevo modelo de gestión, impulsando ideas innovadoras bajo el lema de "Reinventing Government" (Osborne y Gaebler, 1994), cuya base fundamental la constituye la satisfacción al "cliente», es decir, un gobierno verdaderamente orientado al ciudadano como actor protagonista para el Estado.

Tomando como base esas ideas y experiencias de los países desarrollados, las reformas de segunda generación en América latina instaron mejorar la gobernabilidad a través del fortalecimiento institucional y la optimización de la gestión estatal, de manera de postular ya no "menos" Estado, sino un "mejor" Estado, capaz de garantizar condiciones de orden social, estructuras más ágiles y transparentes, creatividad y responsabilidad de los agentes (García Delgado, 1998). Dichas democracias modernas han buscado desarrollar mecanismos que contribuyan a esos fines, siendo la sanción de Leyes de Acceso a la Información Pública y la utilización de tecnologías de información como medio de publicidad de las 
acciones de gobierno, temas centrales de sus procesos de reforma y herramientas básicas de promoción de las nuevas reglas de juego existentes en la relación gobierno - ciudadanía.

La Carta Iberoamericana de Participación Ciudadana en la Gestión Pública del CLAD (2009), refleja este flamante vínculo al reconocer los derechos de la sociedad a inmiscuirse en los diferentes espacios de la gestión pública. Según Oszlak (2012) la Carta plantea un paradigma social que busca una democracia plena basada en los derechos de información, participación, asociación y expresión sobre lo público, o sea, en el derecho de las personas a participar en la gestión pública colectiva e individualmente. $\mathrm{E}$ documento presenta al Derecho de acceso a la información como un derecho que sustenta el adecuado funcionamiento de la democracia puesto que es condición para garantizar otros derechos y, en particular, el de participación ciudadana en la gestión pública. De igual forma, reconoce a la Transparencia como el principio que orienta el proceso de apertura a que los gobiernos deben comprometerse con relación a la ciudadanía.

Concretamente en Argentina, que ha atravesado muchas y largas experiencias de gobiernos militares en los que la información era reservada o secreta, la democracia buscó reconfortar la vida institucional, aunque la corrupción estructural existente en el país atentó contra la transparencia, pilar fundamental del ejercicio de la función pública (Rodríguez Villafañe, 2003). Sin embargo, la reforma constitucional de 1994 resultó un punto de partida importante para avanzar en un proceso de consolidación de una perspectiva más amplia y completa sobre la importancia de la transparencia y el derecho de acceso a la información pública. Un aspecto crucial, que tuvo mucho que ver en ello, fue la incorporación a la Constitución de pactos internaciona- les de particular importancia en la temática.

Teniendo en cuenta estos avances, la investigación se enfoca en realizar un estudio comparado entre las provincias argentinas, para efectuar un diagnóstico sobre el estado de la transparencia y del derecho de acceso a la información pública en cada una de ellas y establecer algunos tópicos de agenda abierta que permitan mejorar la implementación de las diferentes acciones en dichas materias.

Pero dada la amplitud de ambas áreas, y considerando que Argentina comienza a tratar el tema de la transparencia y del acceso a la información pública con énfasis recién a fines de la década del 90 del siglo pasado, para ordenar el análisis fue necesario circunscribirlo a los primeros factores que comienzan por implementarse en las acciones que se desprenden de este tipo de políticas. ${ }^{1}$

Por un lado, desde una perspectiva comparada, se estudiaron las normas locales de las provincias argentinas que reglamentan el derecho de acceso a la información pública, teniendo en cuenta los requisitos mínimos exigidos internacionalmente, especialmente considerando la Ley Modelo de Acceso a la Información Pública de la OEA (2011). ${ }^{2}$ Por otro, a fin de evaluar el cumplimiento de las obligaciones de Transparencia mediante la publicación de información en los Portales Oficiales, se analizaron las páginas Web de los gobiernos provinciales, como herramientas que facilitan el acceso a la información pública y el involucramiento de la población en los asuntos estatales, en el marco del nuevo paradigma del Siglo XXI conocido como "gobierno abierto".

En función de ello, este trabajo pretende dar respuesta a los siguientes interrogantes: ¿Cuentan las provincias argentinas con una legislación en materia de acceso a la información pública, que favorezca la transparencia y la rendición de cuentas?, ¿consideran las normas de acceso a la información dictadas 
por las provincias argentinas los principios fundamentales que deberían garantizar?, ¿disponen las provincias argentinas de información pública en sus portales oficiales que aseguren una consolidación de la cultura de la transparencia?

Para responder a estas preguntas primeramente fue necesario determinar una metodología de medición o métrica, tomando en consideración experiencias ya utilizadas, pero adaptándolas al análisis particular. Para ello, se definió un índice denominado "Índice de Transparencia y de Acceso a la Información Pública" (ITAI), el cual engloba los dos componentes mencionados anteriormente estructurados en dos subíndices. Para cada uno de dichos componentes se identificaron las variables a ser analizadas sin ser exhaustivo ni comprehensivo de todas las variables que pueden considerarse; y para cada una de ellas, se plantearon los indicadores (atributos de cada variable) susceptibles de ser relevados, tanto en los contenidos de las normativas como de los Portales Web. ${ }^{3}$

El Subíndice Calidad Normativa (SICAN) engloba 6 variables: Sujetos Obligados, Información de oficio, Facilidad de acceso a la Información, Información Reservada, Gratuidad de la Información y Fomento al cumplimiento de la Norma. Por su parte, a través del Subíndice de Transparencia en Páginas Web (IPAWE) se han evaluado cuatro áreas de transparencia: Transparencia Institucional, Relación con ciudadanos y la sociedad, Transparencia Económico - Financiera y Transparencia en las contrataciones. ${ }^{4}$

A fin de efectuar el análisis se definieron 4 (cuatro) grados que hacen posible clasificar a las provincias en función del resultado arrojado por el Índice Compuesto. De 0 \% a $25 \%$ el proceso de apertura es "Rezagado", de $26 \%$ a $50 \%$ «Incipiente», de $51 \%$ a $75 \%$ "Satisfactorio" y de $76 \%$ a $100 \%$ "Muy Satisfactorio".
Las realidades halladas fueron más que diversas, pero los datos generales de la investigación muestran que, en la mayoría de los casos, las normativas legales de acceso a la información se alejan notablemente de las disposiciones mínimas propuestas internacionalmente, y que las páginas Web no cuentan con la suficiente cantidad de información que permita a los ciudadanos enterarse de las acciones de gobierno y fiscalizar a la autoridad pública. Es decir, los resultados por provincia muestran que la transparencia y el acceso a la información pública es todavía un reto en la mayoría de los estados subnacionales, aun cuando en el $62,5 \%$ de los distritos existe legislación que reconoce el derecho y el $100 \%$ de los mismos cuenta con Sitios Web oficiales.

Actualmente son nueve (9) los estados subnacionales que no cuentan con una norma de acceso a la información, lo que implica una violación por sí misma del derecho, dado que solo mediante el establecimiento de un marco legal sólido es posible garantizar y promover políticas de transparencia necesarias para erradicar la cultura del secreto implantada en muchos de los gobiernos locales.

Con respecto a los marcos jurídicos sobre acceso a la información, los resultados del SICAN demuestran que el estado general es preocupante, ya que ninguna de las provincias argentinas presenta un nivel "Muy Satisfactorio" en el análisis de la calidad de las normativas. Ello demuestra la incapacidad de los gobiernos provinciales de reglamentar adecuadamente este derecho y de favorecer la transparencia y la rendición de cuentas. Las débiles disposiciones que instituyen, las precarias garantías para el control de la implementación y el cumplimiento de la norma, la dispersión de criterios normativos, hacen que el sistema actual de este derecho fundamental para la democracia se encuentre en un callejón de muy difícil salida. 
En relación al SIPAWE, los diferentes Sitios muestran fortalezas y debilidades relativas, pero la situación general observada no es menos preocupante que la calidad que presentan los marcos jurídicos provinciales, dado que, salvo algunas excepciones, la mayoría de las provincias argentinas no disponen de suficiente información en sus Sitios Oficiales que cercioren una consolidación de la cultura de la transparencia. El escenario se ve agravado al analizar las variables que componen el SIPAWE, dado que las dos dimensiones indispensables para que los ciudadanos puedan conocer el gasto público y fiscalizar a las autoridades, no superan una media del $40 \%$.

Finalmente, esta investigación deja muchos interrogantes por revelar, los cuales pueden ser abarcados por otros estudios relacionados. La discusión sobre la sanción de Leyes de Acceso a la Información Pública, como sobre las decisiones políticas sobre los contenidos de los Portales Web Oficiales, son temas que aún se encuentran en auge en nuestra retrasada sociedad argentina, si lo comparamos con otros países que ya han superado estas etapas y el debate se halla en estadios más avanzados como es el gobierno abierto y la buena gobernanza.

Sobre la base de estas conclusiones, es necesario que los gobiernos demuestren una mayor voluntad política tendiente a afianzar el derecho de acceso a la información, y consolidar los Portales gubernamentales como medios indispensables para acercar el Estado a la ciudadanía, transparentando su accionar. Güemes y Ramírez - Alujaz (2012) afirman que «el desafío es ante todo político, de cambio del ethos cultural en los gobiernos y administraciones, y de generación de capacidades institucionales y confianza de cara a la ciudadanía».

\section{NOTAS}

${ }^{1}$ Transparencia Internacional y el Programa de las Naciones Unidas para los Asentamientos Humanos Un - Hábitat (2004) plantean una serie de herramientas para mejorar la gobernanza local, entre las que se encuentran la sanción de leyes de acceso a la información y el desarrollo del gobierno electrónico como principales acciones para promover la transparencia y mejorar el acceso a la información y la participación ciudadana. 2 La Ley Modelo de Acceso a la Información, además de ser un documento que establece los estándares mínimos en la materia, es un instrumento que sirve de referencia para mejo- rar la calidad de las leyes de los países que ya cuentan con normas y para fortalecer el trabajo de los países que aun no disponen de leyes que garanticen y regulen este derecho.

3 La estructura para la construcción del Índice se tomó de la metodología utilizada por Grandinetti (2014) en su Tesis Doctoral "Diseño de organizaciones públicas locales para la gestión de territorios complejos: Hacia una propuesta metodológica".

4 Para cada indicador se definió su forma de medición y valuación. 


\section{BIBLIOGRAFÍA}

Banco Mundial (1997). Informe sobre Desarrollo mundial 1997. El Estado en un mundo en transformación. Washington: Banco Mundial.

Consejo Latinoamericano de Administración para el Desarrollo (2009). Carta Iberoamericana de Participación Ciudadana en la Gestión Pública.

García Delgado, D. (1998). Estado-nación y globalización. Fortalezas y debilidades en el umbral del tercer milenio. Buenos Aires: Ariel.

Grandinetti, R. M. (2014). “Diseño de organizaciones públicas locales para la gestión de territorios complejos: Hacia una propuesta metodológica”. Tesis Doctoral, Universidad Politécnica de Valencia.

Osborne, D., \& Gaebler, T. (2002). La Reinvención del Gobierno. La influencia del espíritu empresarial en el sector público. Barcelona: Ediciones Paidós Iberica.

Ramírez, M. (2009). Las reformas del Estado y la administración pública en América Latina y los intentos de aplicación del New Public Management. Estudios Políticos, 34, Instituto de Estudios Políticos, Universidad de Antioquía, pp. 115-141.

Rodríguez Villafañe, M. J. (2003). El acceso a la información pública en Argentina. Derecho Comparado de la Información No 2, pp. 111-143. 
